contours on the neighbouring slope and both ellipses are clockwise. No information can be gained about the vertical structure of the currents on the shelf but other records of tidal currents at the same position as mooring 072 in 1961 and 1962 suggest ${ }^{5}$ that the bottom tidal currents had a magnitude of about $69 \%$ of those measured near the surface, that the deep ellipse axes were rotated about $10^{\circ}$ clockwise relative to the surface observations and that there was no phase difference between surface and bottom observations. Thus the observations we have made are probably representative of the tidal currents in the entire water column.

The direct comparison with the near surface observations of Cartwright and Woods ${ }^{5}$ is shown in Table 1. The older data were published in the form of mean ellipses for spring and neap tides and we have calculated the separate $M_{2}$ and $\mathrm{S}_{2}$ ellipses from these. No information on the phases of the $M_{2}$ and $S_{2}$ tidal currents can be extracted from the data of ref. 5 .

The results of the decomposition of the currents from mooring 074 into their modal structure are presented in Table 2 for both periodicities and both data pieces. The modal structures remain constant from one piece to the next and because of the lack of energy in the high order modes are insensitive to the number of modes fitted. The dimensions shown in Table 2 refer to the values at the sea surface.

The difference in the energy distributions as a function of mode numbers between the two tidal components is remarkable. For $\mathrm{M}_{2}$, between 50 and $60 \%$ of the total energy is in the barotropic mode and the remainder is divided almost equally between the first, second and third baroclinic modes. For $\mathrm{S}_{2}$ less than $10 \%$ of the total energy is in the barotropic mode; most of the energy (some $70 \%$ ) is found in the first baroclinic mode and another $10 \%$ or so in the second baroclinic mode (Table 2). This difference in energy distribution is surprising because the modal structures for the two frequencies are almost identical.

Pekeris and Accad ${ }^{6}$ have derived theoretically the barotropic $\mathrm{M}_{2}$ tidal current ellipses at a variety of grid points. The nearest prediction point to the area in which our observations were made is at about $48^{\circ} \mathrm{N}, 16^{\circ} \mathrm{W}$. This is not very close to the observation area but the agreement between the observations and predictions is good. The dimensions of the predicted $\mathrm{M}_{2}$ ellipse are greater than those observed (Table 2) but Pekeris and Accad found that their predictions of the tidal ranges for the North Atlantic exceeded the observed values (Table 3 of ref. 6); however, the agreement in terms of the shapes, orientations and phases of the observed $\mathrm{M}_{2}$ tidal ellipses is good.

In spite of the shortness of the current records the results presented here show that the observations of tidal current ellipses for both $M_{2}$ and $S_{2}$ give consistent results which are in agreement, in the case of the continental shelf observations, with previous observations and, for the deep water, with theoretical predictions of $\mathbf{M}_{2}$. The difference in the modal decomposition between the two species is difficult to account for but may result from the local topography and its relation to the directions of propagation of the two tidal components.

The analysis of these data was performed when we were at the Woods Hole Oceanographic Institution. The work was supported by the Office of Naval Research.

National Institute of Oceanography,

W. J. Gould

Wormley, Surrey

Department of Mathematics,

W. D. MCKeE

Monash University,

Clayton, Victoria, Australia

Received February 23; revised March 28, 1973.

1 Aanderaa, I. R., Fixed Buoy Project, Tech. Rep. No. 16 (NATO Sub-committee on Oceanographic Research, 1964).

2 Maagard, L., and McKee, W. D., Deep-Sea Res. (in the press).

3 Krauss, W., Interne Wellen (Gebrüder Borntraeger, Berlin, 1966).
${ }^{4}$ Singleton, R. C., IEEE Trans. on Audio and Electroacoustics, AU-17 (2), 93 (1969)

5 Cartwright, D., and Woods, A. J., Deutsche Hydrograph. Zeit., 16, 64 (1963).

' Pekeris, C. L., and Accad, Y., Phil. Trans. Roy. Soc., A, 265, 413 (1969).

\section{Palaeozoic Tethyan Ocean}

THE statement by Burret $t^{1}$ that there is "no evidence for the existence of a Tethyan Ocean in the Palaeozoic" is incorrect. I refer to a symposium on Aspects of Tethyan Biogeography published by the Systematics Association in 1967 (ref. 2). In that volume one of the first articles was by Sdzuy, entitled The Tethys in Cambrian Time. The Bulletin of the American Association of Petroleum Geologists for October 1972 contains an article entitled Permian Tethys and the Indian Ocean ${ }^{3}$. The concept of a Palaeozoic Tethys is so well established in geological literature that a list of references would probably include several thousand titles.

University of Kansas Paleontological Institute,

Lawrence,

Kansas 66044

Received November 6, 1972.

${ }^{1}$ Burrett, C. F., Nature, 239, 155 (1972).

2 Systematics Association, Spec. Publ. 7 (edit. by Adams, C. G., and Ager, D. V.) (Systematics Association, London, 1967).

${ }^{3}$ Kamen-Kaye, M., Bull. Amer. Assoc. Petrol. Geol., 50, 1984 (1972).

\section{Reply}

THE sentence which Teichert objects to is, when taken in context, a criticism of Nicholas's assumption ${ }^{1}$ of the existence of an ocean between Southern Europe and Africa. In geological discussions an ocean may be defined as a deep basin floored by simatic crust generated by the accretion of basaltic material at linear ridges of active volcanism and seismicity ("mid-ocean ridges"). Oceanic growth is accomplished by the process unfortunately known as "seafloor spreading". The Red Sea is an example of an incipient ocean and the Atlantic an example of a fully fledged ocean. This definition would exclude those expanses of salt water usually included in oceans which cover continental crust. These expanses are seas. Clear differentiation between oceans and seas is important in palaeogeographic and tectonic discussions. Nicholas ${ }^{1}$ was clearly using his Tethys in the sense defined above with the plate tectonic embellishment of a subducting margin. My communication ${ }^{2}$ arose out of a worldwide, quantitative analysis of Ordovician biogeography (unpublished). The conclusion that the faunal distributions found are best interpreted in terms of oceanic barriers rather than in terms of climate or other ecological factors is also justified elsewhere. Johnson's Provinciality Index ${ }^{3}$ was used to compare pairs of geographical areas. This index is calculated by dividing the number of common fossil genera by twice the number of endemic genera in the smaller faunal list. Values above one are taken to indicate some degree of co-provincialism. In this study values have ranged from $0-5.2$, with most values falling within the range $0.1-0.7$. Of all pairs of areas, the comparison between North Africa and Southern Europe gave, by far, the highest values (Fig. 1). On the other hand, indices between Southern Europe and Northern Europe were very low (Fig. 1). Somewhat more sophisticated computerized studies of Cambrian faunal provinces are in preparation by Burrett and Richardson. These 